\title{
In vitro Permeation Study of Ketoprofen Patch with Combination of Ethylcellulose and Polyvynil Pyrrolidone as Matrix Polymers
}

\author{
Soraya Ratnawulan Mita*, Patihul Husni, Dewi Setiyowati \\ Faculty of Pharmacy, Universitas Padjadjaran, Jatinangor, INDONESIA.
}

\begin{abstract}
Objective: Transdermal patch can release drug to provide systemic pharmacological effect. Matrix used in the patch formula influences the release of the drug. The aim of the study was to evaluate permeation of Ketoprofen patch containing combination of Ethyl Cellulose (EC) and Polyvynil Pyrrolidone (PVP) as matrix. EC is a hydrophobic polymer while PVP is a hydrophilic one. Transdermal formulation containing two polymers with different polarity will provide better permeation results than use only one type of polymer. Ketoprofen $1 \%$ was used as a model of active substance in the study. Methods: Ratio of EC and PVP concentration (1:1, 1:3 and 3:1) in patch formula was determined using Simplex Lattice Design (SLD) method. In vitro permeation study was done for $12 \mathrm{~h}$ using Franz diffusion cell and shed snake of Phyton reticulatus as a membrane. Amount of the drug released was analyzed using Spectrophotometer UV-Vis $(\lambda=262 \mathrm{~nm})$. The drug release mechanism was known by determination the drug release kinetics order. Results: The study result showed that the higher PVP concentration was used in the formula, the higher percentage of Ketoprofen permeation
\end{abstract}

was obtained. Patch formula containing EC:PVP in ratio 1:3 had the highest percentage of permeation (93.66\%). The drug release kinetics of Ketoprofen from the patch followed zero order kinetics. Conclusion: Combination of EC and PVP in ratio 1:3 resulted the highest percentage of ketoprofen permeation for $12 \mathrm{~h}(93.66 \%)$. The drug release mechanism followed zero order kinetics.

Key words: Ethylcellulose, Ketoprofen, Patch, Permeation, Polyvynil pyrrolidone, Simplex Lattice Design.

\section{Correspondence}

Soraya Ratnawulan Mita, Faculty of Pharmacy, Universitas Padjadjaran, Jatinangor, INDONESIA

Phone: +62 85322744100

Email: soraya@unpad.ac.id

DOI: 10.5530/jyp.2018.2s.20

\section{INTRODUCTION}

Oral ketoprofen is an effective therapy to relieve pain. The clinical use of ketoprofen is very limited because of its side effect on cardiovascular and gastrointestinal. ${ }^{1}$ Administration of Ketoprofen using transdermal system is an alternative which can be used to avoid the side effect. Many studies show that Ketoprofen is more effective than others NSAID (Non-Steroidal Anti Inflammantory Drug) such as Diclofenac and Ibuprofen. Effect of Ketoprofen as an analgesic is very good and fast. ${ }^{2}$

The problem of transdermal administration is a barrier provided by human skin for the drug to permeate..$^{3-4}$ Enhancer is one of methode that can approach amount of drug permeation in the transdermal drug design. ${ }^{5-7}$ Beside that, polymer that used in formula also can affect drug release, permeability, elasticity and character of the formula. ${ }^{8}$

Combination of hydrophobic and hydrophilic polymer has been used as a matrix polymer. ${ }^{9}$ Ethylcelulose (EC) is a hydrophobic polymer commonly used in transdermal preparation. EC is not only a polymer that has low solubility in water, not toxic, and not irritate but also it does not cause allergy and can form strong film layer. ${ }^{10}$ Combination of $1,5 \% \mathrm{EC}$ and dibutyl phthalate as a plasticizer can release $99.12 \%$ hydrophobic Amlodipine for $24 \mathrm{~h}$ but the percentage of drug released will decrease if the EC used is in high concentration. ${ }^{11}$

In the other hand, Polyvynil pyrrolidone (PVP) is a low toxicity hydrophilic polymer. PVP can increase solubility of the low soluble substance and does not cause irritate on the skin. ${ }^{12}$ Study of Patel et al. showed that increase of PVP concentration may release a combination drug of Hydrochlorothiazide and Lisinopril (hydrophobic and hydrophilic drugs) more than $80 \%$ for less than 8 h. ${ }^{3}$ Solubility of PVP in water can increase water penetration into the matrix so that the drug release occurs rapidly.
Santosh and Jyoti studied about effect of combination EC and PVP polymer in Ketoprofen patch. EC:PVP was formulate in ratio 4:1 and resulted transparent and soft surface patch without air bubble. EC:PVP in ratio $4: 1$ can release the drug about $97.87 \%$ for $24 \mathrm{~h}$ in vitro. ${ }^{14}$ In vitro study done by Prabu et al. showed that use of EC: PVP in ratio 1:3 released hydrophobic drug (Dexibuprofen) in the maximum amount after $24 \mathrm{~h}$. In contrast, combination of EC:PVP in ratio 3:1 showed the lowest drug release after 24 h. ${ }^{15}$

The previous studies above showed that polymers play an important role in controlling drug release from the system. ${ }^{16}$ Selection of the polymer combination can be optimized computationally using the Simplex Lattice Design (SLD) program to get the optimum formula. SLD method is used to optimize the formula based on physical parameter of the preparation in various amount of different material composition. The advantage of SLD method are faster, more practical and more efficient method than determination of the by trial and error. ${ }^{17-18}$

Based on the background above, Formulation of Ketoprofen patch preparation containing combination of hydrophobic polymer (ES) and hydrophilic polymer (PVP) that is optimized using SLD program and its in vitro permeation study had been done.

\section{MATERIALS AND METHODS}

\section{Materials}

Ketoprofen (PT. Kimia Farma), ethylcellulose (Merck), PVP (Merck), dibutyl phtalate (Merck), tween 80 (Merck), cloroform (Merck), $\mathrm{KH}_{2} \mathrm{PO}_{4}, \mathrm{NaOH}$, dan Aquadest. Skin layer of shed snake Phyton reticulatus was obtained from Bandung Zoo. The following equipment were used:

This is an open access article distributed under the terms of the Creative Commons Attribution-NonCommercial-ShareAlike 4.0 License, which allows others to remix, tweak, and build upon the work non-commercially, as long as the author is credited and the new creations are licensed under the identical terms. 
franz diffusion cell, digimatic heightgage (Mitutoyo), $\mathrm{pH}$ meter (Schott Instrument Lab 850), magnetic stirrer (Yellow-MAG HS7), pH meter, Spectrophotometer UV-Vis (Analytic Jena-Specord 200), analytical balance (Adventure TM-OHAUS), syringe, software Design-Expert versi 7.0 and software SPSS Version 21.

\section{Methods}

\section{Determination of formula using simplex lattice design} (SLD)

Formula of Ketoprofen patch was selected using SLD program to get the most optimum Ketoprofen patch formula containing combination of EC and PVP. Experimental design was done on two components (EC and PVP) by changing the concentration of EC and PVP with constant total concentration. Response or parameters used are humidity, homogeinity and percentage of permeation.

\section{Formulation of ketoprofen patch}

Formula of Ketoprofen patch is listed in Table 1. Ketoprofen was dissolved in chloroform in different beaker glass and then tween 80 as penetration enhancer and dibutyl phtalate as plasticizer was added. Each polymer was dissolved in chloroform under stirring by magnetic stirrer. Both of the polymers was mixed and added with solution containing Ketoprofen, tween 80 and dibutyl phtalate. Chloroform was added into the solution up to $100 \%$. The solution was stirred homogenously. The homogenous solution was spread into a petri dish which had been coated with aluminum foil paper and dried at room temperature. ${ }^{14}$

\section{Evaluation of patch thickness}

Patch thickness was measured using a caliper at six different sites of the patch, then determined the average and its deviation standard. ${ }^{11}$

\section{Humidity test of patch ketoprofen}

Patches weighed and then stored in a desiccator containing $\mathrm{KCl}$ at room temperature for $24 \mathrm{~h}$. Patches weighed back at a specified time interval until it weighs the constant. ${ }^{11}$ The percentage of moisture can be calculated via the formula:

\section{Homogeneity test of ketoprofen content in patch}

Patch was randomly taken and divided into four parts. Each patch was dissolved into $25 \mathrm{~mL}$ of chloroform in a measuring flask. $0.2 \mathrm{~mL}$ solution was taken and dissolved into $10 \mathrm{ml}$ chloroform. The four solutions were filtered and measured absorbance using UV-Vis Spectrophotometry at a wavelength $257 \mathrm{~nm}$. The content results of the four patches are summed, so the ketoprofen content in the patch preparation can be known.

Table 1: Formula of ketoprofen patch.

\begin{tabular}{cccc}
\hline \multirow{2}{*}{ Ingredients } & \multicolumn{3}{c}{ Formula $(\%, \mathrm{~b} / \mathrm{b})$} \\
\cline { 2 - 4 } & $\mathrm{F} 1$ & $\mathrm{~F} 2$ & $\mathrm{~F} 3$ \\
\hline Ketoprofen & 1 & 1 & 1 \\
Ethylcellulose & $5^{*}$ & $2,5^{*}$ & $7,5^{*}$ \\
PVP & $5^{*}$ & $7,5^{*}$ & $2,5^{*}$ \\
Tween 80 & 3 & 3 & 3 \\
Dibutyl phtalate & 30 & 30 & 30 \\
Chloroform $^{*}$ & Add 100 & Add 100 & Add 100 \\
\hline
\end{tabular}

$\left(^{*}\right.$ based on result of SLD program. $\left(^{* *}\right)$ percentage was based on dry weight of polymer (30\% x dry weight of polymer)

\section{In vitro permeation study of ketoprofen patch}

In vitro permeation study was done using Franz diffusion cell and phosphate buffer $\mathrm{pH} 7.4$ as permeation media in receptor compartment. ${ }^{19-20}$ The phosphate buffer used was isotonic solution which has $\mathrm{pH} 7.4$ as same as body fluid. Skin layer of shed skin snake Phyton reticulatus was used as membrane $\left(3 \mathrm{~cm}^{2}\right)$. A magnetic bar and $21 \mathrm{~mL}$ phosphate buffer $\mathrm{pH} 7.4$ at $37^{\circ} \mathrm{C}$ was used in receptor compartment. $3 \mathrm{~cm}^{2}$ of patch as donor compartment was placed on membrane (shed skin snake) and installed on franz diffusion cell apparatus. The permeation study was done under stirring by magnetic stirrer. Content of Ketoprofen permeated was calculate by measuring the absorbance of buffer solution sample collected from receptor compartment. $1 \mathrm{~mL}$ buffer solution was collected using a syringe and diluted with $5 \mathrm{ml}$ buffer solution. The $1 \mathrm{~mL}$ collected buffer solution was replaced by $1 \mathrm{~mL}$ fresh buffer solution. Sample was collected at $1,2,3,4,5,6,7,8,9,10,11$, dan 12 h of permeation study and then absorbance of the sample was measured using Spectrophotometer UV-Vis at wavelength $262 \mathrm{~nm}$. Patch without ketoprofen (placebo patch) was also run for the permeation study as same as the sample (ketoprofen patch). The placebo patch was used as blank.

\section{Determination of Kinetics Order of Drug Release}

The release mechanism of transdermal patch can be determined by the kinetics order of drug release. Zero order kinetics is determined by the plotting the percentage of release versus time (h), first order kinetics by plotting the logarithmic value of release versus time (h) and the Higuchi order kinetics is determined by making a percentage release of drug versus the square root of time.

\section{RESULTS}

\section{Determination of formula using simplex lattice design (SLD)}

Based on the interval of concentration used, the formula was EC:PVP in ratio $5 \%: 5 \%, 2.5 \%: 7.5 \%$ and $7.5 \%: 2.5 \%$. Total of polymer concentration was $10 \%$.

\section{Formulation of ketoprofen patch}

The patch preparation was a homogenous, thin, not dry, flexible, smooth and glossy patch (Figure 1).

The thickness of patch were measured by a caliper ${ }^{15}$ and the results showed at Table 2 .

The moisture percentage of a patch is calculated from the difference of initial and final weight after storage. Low humidity in the formulation is able to keep the preparation stable and the film not dry and fragile. ${ }^{10}$ The moisture percentage can be seen in Table 3 .

Homogenity tests of ketoprofen content were performed to ensure that on each part in a patch had a uniform content of ketoprofen (Table 4). Testing was done on a patch divided into four parts.

\section{In vitro permeation study of ketoprofen patch}

Measurement of ketoprofen was done with a UV visible spectrophotometer with a placebo patch as blanko. Before performing the measurement the sampling results of ketoprofen permeation rate, first performed measurement of spectrophotometer against placebo patches at the same sampling time (Figure 2).

The result of permeation Ketoprofen is showed at Table 3. Formula with EC 2.5\% : PVP 7.5\% has highest percentage of permeation with average permeation per hour is $40.91 \%$.

Figure 3 showed that formula containing polimer combination EC:PVP in ratio 1:3 (F2) had the highest cumulative AUC (164.121 mcg.hr/mL) 


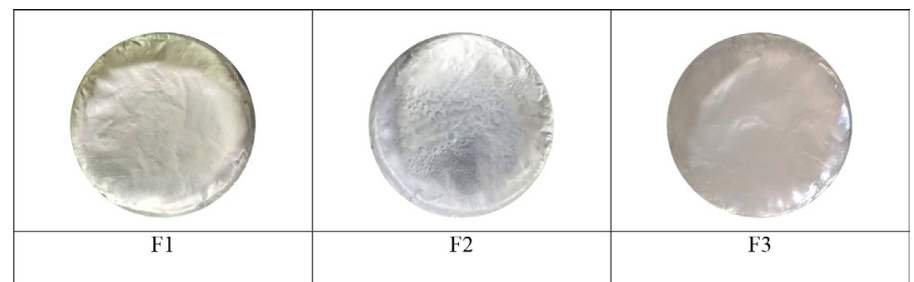

Figure 1: Patch ketoprofen.

Notes: $\mathrm{F} 1$ = EC 5\% : PVP 5\%; F2 = EC 2.5\% : PVP 7.5\%; F3 = EC 7.5\% : PVP 2.5\%

Table 2: The tesults of thickness test $(n=3)$.

\begin{tabular}{cccc}
\hline \multirow{2}{*}{ No. } & \multicolumn{3}{c}{ Thickness $(\mathbf{m m})$} \\
\cline { 2 - 4 } & F1 & F2 & F3 \\
\hline 1. & 0,244 & 0,212 & 0,200 \\
2. & 0,242 & 0,210 & 0,174 \\
3. & 0,194 & 0,218 & 0,208 \\
Average \pm SD & $0,227 \pm 0,028$ & $0,213 \pm 0,004$ & $0,194 \pm 0,017$ \\
\hline
\end{tabular}

Table 3: Humidity test result of ketoprofen patch $(n=3)$.

\begin{tabular}{cccc}
\hline \multirow{2}{*}{ No. } & \multicolumn{3}{c}{ Humidity (\%) } \\
\cline { 2 - 4 } & F1 & F2 & F3 \\
\hline 1. & 3.374 & 3.916 & 1.743 \\
2. & 3.072 & 3.670 & 1.844 \\
3. & 3.377 & 3.266 & 1.987 \\
Mean \pm SD & $3.274 \pm 0.176$ & $3.617 \pm 0.328$ & $1.858 \pm 0.122$ \\
\hline
\end{tabular}

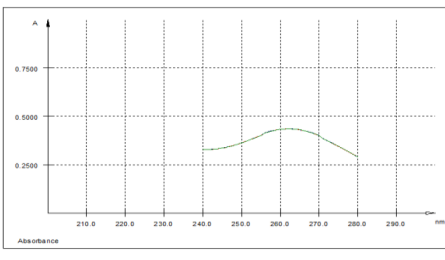

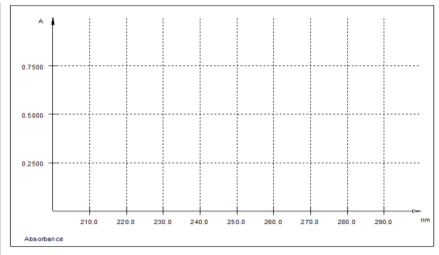

B
Figure 2: Spectrum UV visible at wave length $262 \mathrm{~nm}$ at buffer phosphate $\mathrm{pH} 7.4$.

Notes: $\mathrm{A}=$ Sampling solution of ketopropen patch. $\mathrm{B}=$ Sampling solution of placebo patch.

Table 4: Homogenity test result of ketoprofen content in the patch $(n=4)$.

\begin{tabular}{cccc}
\hline \multirow{2}{*}{ No. } & \multicolumn{3}{c}{ Content (\%) } \\
\cline { 2 - 4 } & F1 & F2 & F3 \\
\hline 1. & 7.414 & 7.544 & 7.473 \\
2. & 7.273 & 7.426 & 7.232 \\
3. & 7.316 & 7.201 & 7.323 \\
4. & 7.130 & 7.392 & 7.516 \\
Mean \pm SD & $7.283 \pm 0.118$ & $7.391 \pm 0.142$ & $7.386 \pm 0.132$ \\
CV & 1.619 & 1.926 & 1.785 \\
\hline
\end{tabular}

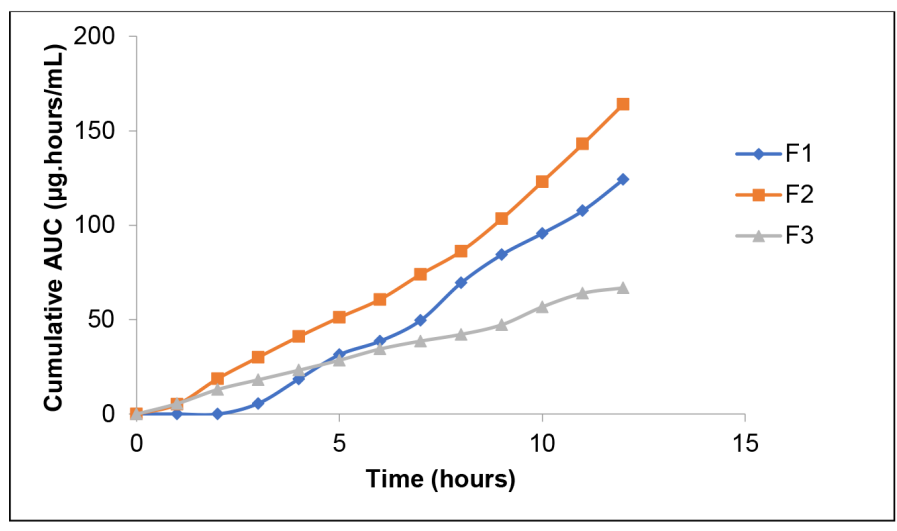

Figure 3: Profile of cumulative AUC ketoprofen patch $(n=3)$. F1 (EC 5\% and PVP 5\%). F2 (EC 2.5\% and PVP 7.5\%). F3 (EC 7.5\% and PVP 2.5\%).

while F1 and F3 were $124.223 \mathrm{mcg} . \mathrm{hr} / \mathrm{mL}$ and $66.851 \mathrm{mcg} . \mathrm{hr} / \mathrm{ml} \%$ respectively.

The amount of cumulative AUC of Ketoprofen permeated through shed skin snake Phyton reticulatus into receptor solution as a function of time. It's shown in Figure 3.

The release mechanism of transdermal patch can be determined by the kinetics order of drug release. The order were determined by the correlation coefficient that close to 1 on each kinetics order. The results were shown in Table 6. The drug release kinetics of Ketoprofen from the patch followed zero order kinetics.

\section{DISCUSSION}

Ketoprofen patch preparation was formulated using combination of EC and PVP polymer. Polymer ratio of EC and PVP was determined using SLD method on Design Expert program. Concentration interval EC and PVP used was $0-10 \%$. The Ketoprofen patch was formulated with EC:PVP in ratio 5\%:5\%, 2.5\%:7.5\% and 7.5\%:2.5\%. Total of polymer concentration was $10 \%$. The concentration interval of the both polymer given sustained release effect so that it is suitable for transdermal patch preparation. ${ }^{12}$ The polymer concentration play an important role in film forming. ${ }^{13}$

Patch was made by solvent evaporation method using chloroform as a solvent. Patch containing combination of EC:PVP polymer and chloroform resulted a homogenous, thin, not dry, flexible, smooth and glossy patch. The thickness of the patch is an important parameter in the evaluation of preparations. The results of measurements of the average thickness of the patch shows a small standard deviation value that is less than 0.03 . F3 has a lower moisture percentage than other formulas. This may be due to the high hydrophobic (EC) content that cannot absorb water. ${ }^{11}$ The higher PVP was used in the formula, the higher percentage of moisture was found in the patch, this is due to the hygroscopic properties of PVP. ${ }^{12}$ Water absorption of the polymer may affect the drug release profile. Based on the evaluation results in Table 3, all the formulas have met the requirements because they have moisture percentage less than $10 \% .{ }^{21}$

Content homogeneity indicates that the drug is dispersed equally in the matrix. Based on the test results, the average content of all formulas (F1, F2, F3) were $7.283 \mathrm{mg}, 7.391 \mathrm{mg}$ and $7.386 \mathrm{mg}$, respectively. Theoretically, ketoprofen content in each patch part was $7.5 \mathrm{mg}$. Evaluation data showed that ketoprofen content was between 7.130 - $7.543 \mathrm{mg}$ with relative standard deviation (\%CV) average 1.77. Based on the value of $\mathrm{CV}$ percentage, there was found homogeneous ketoprofen content as it fulfilled the relative standard deviation criteria of $\leq 2 \% .{ }^{22}$ The results of determining the homogeneity of ketoprofen content can be seen in Table 4 . 
Table 5: Cumulative AUC of permeation ketoprofen patch.

\begin{tabular}{cccc}
\hline \multirow{2}{*}{$\begin{array}{c}\text { Time } \\
\text { (hours) }\end{array}$} & \multicolumn{3}{c}{ AUC $(\boldsymbol{\mu g} \cdot$ hours $/ \mathrm{mL})$} \\
\cline { 2 - 4 } 0 & F1 & F2 & F3 \\
\hline 1 & 0.000 & 0.000 & 0.000 \\
2 & 0.000 & 5.114 & 5.528 \\
3 & 0.000 & 18.755 & 13.022 \\
4 & 5.617 & 30.064 & 18.157 \\
5 & 18.585 & 41.015 & 23.217 \\
6 & 31.428 & 51.183 & 28.545 \\
7 & 38.600 & 60.705 & 34.450 \\
8 & 49.599 & 73.971 & 38.644 \\
9 & 69.447 & 86.208 & 42.199 \\
10 & 84.386 & 103.365 & 47.273 \\
11 & 95.637 & 122.983 & 56.757 \\
12 & 107.669 & 142.999 & 63.987 \\
\hline
\end{tabular}

Table 6: Value of correlation coefficient.

\begin{tabular}{cccc}
\hline \multirow{2}{*}{ Formula } & \multicolumn{3}{c}{ Correlation coefficient $(\mathrm{r})$} \\
\cline { 2 - 4 } & Zero order & First order & Higuchi \\
\hline F1 & 0.969 & 0.867 & 0.815 \\
F2 & 0.978 & 0.794 & 0.857 \\
F3 & 0.989 & 0.757 & 0.930
\end{tabular}

F1 (EC 5\% and PVP 5\%), F2 (EC 2.5\% and PVP 7.5\%), F3 (EC 7.5\% and PVP $2.5 \%)$

In vitro studies were used to predict the rate and determine the amount of drug that actually release from the patch. The polymer dissolution rate was the most important aspect to ensure that patch would release the drug in sustained release pattern. ${ }^{15}$ Three formula were tested to determine the in vitro release profile. Polimers variation would cause the different properties and release pattern ot the patch. ${ }^{23}$ Drug release from the matrix system would be rapid at the start and decreased by the time until the matrix fully dissolved. Amount of drug in the matrix and the matrix properties would affect the rate of drug release in transdermal therapeutic system. ${ }^{15}$

Permeation study were performed using Franz diffusion cell and the drug concentration was determined using spectrophotometer UV-Vis. Placebo patch did not give any absorption as it showed in Figure 2. Permeation profile of Ketoprofen patch are illustrated in Figure 3.

The results of AUC calculations of ketoprofen permeation can be seen in Table 5. Based on the permation study result, F2 showed the highest release by $93.66 \%$ (cumulative AUC $164.121 \mu \mathrm{m}$. hours $/ \mathrm{ml}$ ), followed by $\mathrm{F} 1$ by $72.15 \%$ (cumulative AUC $124.223 \mu \mathrm{m}$. hours $/ \mathrm{ml}$ ) and F3 showed the lowest drug release by $37.69 \%$ (cumulative AUC $66.851 \mu \mathrm{m}$. hours $/ \mathrm{ml}$ ). F2 and F3 released the drug rapidly right from the first hour, but F3 just started release the drug at the third hour by $6.03 \%$. Increasing the amount of PVP in the formula resulted in an increased in the rate of drug release. PVP is a hydrophilic molecule that would increase the wettability and water penetration of the matrix, thus, would increase the diffusion rate of drug. ${ }^{13}$ Research of Prabu et al. showed that improving of PVP cause an increase in the value of Dexibuprofen permeation in transdermal drug design. ${ }^{15}$ Dexibuprofen has physicochemical properties resembling Ketoprofen. Both of them carboxylate group. In this study, increasing PVP (F2; EC: PVP 1:3) also caused of increase Ketoprofen permeation. The lower release rate that exhibited by the formula that contain ES may be due to the hydrophobic properties of the polymer that retain the drug in the matrix and decreased the penetration of solvent. ${ }^{11}$

In addition to being affected by polymers, drug release also influenced by the presence of enhancer. Tween 80 has been used widely as a penetration enhancer in transdermal drug delivery system. Tween 80 would dissolve the lipid in stratum corneum so the drug can penetrate across the membrane. ${ }^{24}$ Plasticizer (Dibuthyl phtalate) is often corporated in transdermal delivery system to give flexibility to the formulation, which improves contact between skin and patch, which lead to an increase permeability and flexibility of drug. ${ }^{15}$

Polymer variation would cause the difference profile on drug release. The order were determined by the correlation coefficient that close to 1 on each kinetics order. The results are shown in Table 6.

By the correlation coefficient value, the drug release profile fit the pattern of zero order kinetic. This means, the drug from the patch were release with a constant rate and did not affected by drug concentration. Zero order released kinetic is the most suitable system for sustained release transdermal delivery system..$^{25}$

\section{CONCLUSION}

Patch formula containing polimer combination EC:PVP in ratio 1:3 resulted the highest percentage of ketoprofen permeation for $12 \mathrm{~h}$ (93.66\%) with accumulative amount of AUC is $164 \mu \mathrm{m}$. hrs $/ \mathrm{mL}$. The drug release mechanism followed zero order kinetics.

\section{ACKNOWLEDGEMENT}

This project was supported by Universitas Padjadjaran under Internal Unpad Grant Program, project RFU No. 115/ 2017.

\section{CONFLICT OF INTEREST}

The authors declare no conflict of interest.

\section{ABBREVIATIONS}

EC : Ethyl Cellulose; PVP : Polyvynil Pyrrolidone; SLD : Simple Lattice Design; NSAID : Non Steroidal Anti Inflammatory; UV Vis : Ultra Violet Visible Spectrophotometric; AUC : Area Under Curve; SD : Standard of Deviation; $\mathbf{C V}$ : Coefisien of Variation.

\section{REFERENCES}

1. FDA. Ketoprofen. Available from: http://www.accessdata.fda.gov/drugsatfda_ docs/label/2007/ 019816s011 lbl.pdf [Accessed 25th January 2017].

2. Sarzi-Puttini P, Atzeni F, Lanata L, Bagnasco M, Colombo M, Fischer $F$, et al. Pain and ketoprofen: what is its role in clinical practice? Reumatismo. 2010;62(3):172-88. Available from: doi:10.4081/reumatismo.2010.172.

3. Rajni K, Rohit BN, Neeraj B. Review on transdermal patch. World J Pharm Pharm Sci. 2016;5(5):492-510. Available from: doi:10.20959/wjpps20165-6708.

4. Raza R, Mittal A, Kumar P, Alam S, Prakash S, Chauhan N. Approach and evaluation of transdermal drug delivery system. Int J Drug Dev and Res. 2015;7(1):222-33

5. Williams AC, Barry BW. Penetration enhancer. Adv Drug Deliv Rev. 2004;56(5):603-18. Available from: doi:10.1016/j.addr.2003.10.025.

6. Arora A, Kisak E, Karande P, Newsam J, Mitragotri S. Multicomponent chemical enhancer formulations for transdermal drug delivery: more is not always better. J Control Release. 2010;144(2):175-80. Available from: doi:10.1016/j.jconrel.2010.02.015

7. Marwah H, Garg T, Goyal AK, Rath G. Permeation enhancer strategies in transdermal drug delivery. Drug Deliv. 2016;23(2):564-78. Available from: doi:10.310 9/10717544.2014.935532.

8. Aktar B, Erdal MS, Sagirli O, Güngör S, Özsoy Y. Optimization of biopolymer based transdermal films of metoclopramide as an alternative delivery approach. 
Polymers. 2014;6:1350-65. Available from: doi:10.3390/polym6051350.

9. Kulakofsky J, Liu P. Multi-polymer compositions for transdermal drug delivery. Patent Application Publication. Patent No. US9, US 9295726. 2016. Available from: https://patentimages.storage.googleapis.com/6c/4e/3b/19bf66594a2ad6/ US9295726.pdf. [Accessed 25th January 2017].

10. Patel DP, Setty CM, Mistry GN, Patel SL, Patel TJ, Mistry PC, et al. Development and evaluation of ethyl cellulose-based transdermal films of furosemide for improved in vitro skin permeation. AAPS PharmSciTech. 2009;10(2):437-42. Available from: doi: 10.1208/s12249-009-9224-3.

11. John L, Kumar A, Samuel S. Formulation and evaluation of Amlodipine transdermal patches using ethyl cellulose. Int Res J Pharm. 2013;4(10):84-8. Available from: doi:10.7897/2230-8407.041019.

12. Rowe RC, Sheskey PJ, Quinn ME. Handbook of pharmaceutical excipient. 6th Edition. UK: Royal Pharmaceutical Society of Great Britain. 2009.

13. Patel N, Prabhu P, Dubey A, Kamath JV. Design and evaluation of buccal patch containing combination of hydrochlorthiazide and lisinopril. RGUHS J Pharm Sci. 2015;5(4):142-54. Available from: doi:10.5530/rjps.2015.4.4.

14. Santosh K, Jyoti M. Formulation and evaluation of transdermal patches of ketoprofen drug. Int J Pharmtech Res. 2013;5(2):670-3.

15. Prabhu SL, Prakash TN, Thiyagarajan S, Amritha M, Manibharati R, Priyadharsini $\mathrm{N}$. Design and evaluation of matrix diffusion controlled transdermal patches of dexibuprofen. J Appl Res. 2012;12(1):38-46.

16. Gaikwad AK. A review: Transdermal drug delivery system: Formulation aspects and evaluation. Compr J Pharm Sci. 2013;1(1):1-10.
17. Bolton S. Pharmaceutical statistic: Practical and clinical applications. 3rd Edition. New York: Marcel Dekker Inc. 1997.

18. Duangjit S, Mehr LM, Kumpugdee-Vollrath M, Ngawhirunpat T. Role of simplex lattice statistical design in the formulation and optimization of microemulsions for transdermal delivery. Biol Pharm Bull. 2014;37(12):1948-57.

19. Bartosova L, Bajgar J. Transdermal drug delivery in vitro using diffusion cells. Curr Med Chem. 2012;19(27):4671-7. Available from: doi:10.2174/ 092986712803306358.

20. Seo JE, Kim S, Kim BH. In vitro skin absorption tests of three types of parabens using a Franz diffusion cell. J Expo Sci Environ Epidemiol. 2017;27(3):320-5. Available from: doi: 10.1038/jes.2016.33

21. Kumar VS, Niranjan SK, Irchhaiya R, Neeraj K, Ali A. A novel transdermal drug delivery system. Int Res J Pharm. 2012;3(8):39-44.

22. Ahuja S, Dong MW, Editors. Handbook of pharmaceutical analysis by HPLC. Volume 7. New York: Elsevier Academic Press. 2005.

23. Modi C. Effect of components (polymer, plasticizer and solvent) as a variable in fabrication of diclofenac transdermal patch. J Pharm Bioallied Sci. 2012;4(1):S57-9. Available from: doi:10.4103/0975-7406.94129.

24. Trommer $\mathrm{H}$, Neubert RH. Overcoming the stratum corneum: The modulation of skin penetration. A review. Skin Pharmacol Physiol. 2006;19(2):106-21. Available from: doi:10.1159/000091978.

25. Dash S, Murthy PN, Nath L, Chowdhury P. Kinetic Modelling on Drug Release from Controlled Drug Delivery Systems. Acta Pol Pharm. 2010;67(3):217-23.

Article History: Submission Date : 19-01-2018 ; Revised Date : 10-03-2018; Acceptance Date : 14-05-2018.

Cite this article: Mita SR, Husni P, Setiyowati D. In vitro Permeation Study of Ketoprofen Patch with Combination of Ethylcellulose and Polyvynil Pyrrolidone as Matrix Polymers. J Young Pharm. 2018;10(2)Suppl:s101-s105. 